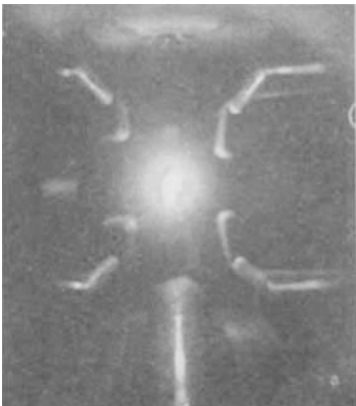

(a)

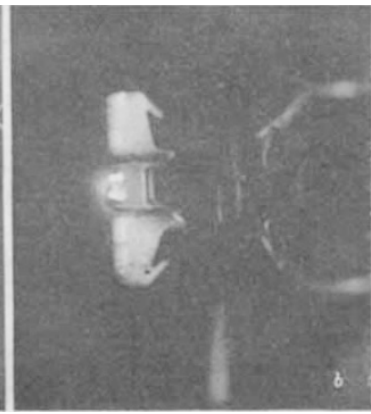

(b)
Fig. 2. (a) Tip of the ion source at the centre of the cyclotron when the machine is accelerating molecular hydrogen ions. (b) Same as (a), except that the machine is accelerating deuterons. The bright patch on the left-hand side is part of the dee-structure

fringing field of the cyclotron and the field of the deflecting magnet, combined with slit systems in the path of the beam, can be used to provide an analysed beam with an energy spread of less than 1 per cent of its mean energy. The cyclotron is normally used for accelerating deuterons $\left(\mathrm{D}^{+}\right)$, molecular hydrogen ions $\left(\mathrm{H}_{2}{ }^{+}\right)$or alpha particles $\left(\mathrm{He}^{++}\right)$, for each of which resonance can be obtained at the frequency of $10.24 \mathrm{Mc} . / \mathrm{s}$. by relatively small variations of the magnetic field. Each molecular hydrogen ion of energy $20 \mathrm{MeV}$. is equivalent for transmutation purposes to two protons of $10 \mathrm{MeV}$. The beam currents normally obtainable are shown in the accompanying table.

\begin{tabular}{|c|c|c|c|c|c|c|}
\hline \multirow{2}{*}{$\begin{array}{c}\text { Ion } \\
\text { acceler- } \\
\text { ated }\end{array}$} & \multirow[b]{2}{*}{$\begin{array}{l}\text { Fnergy } \\
\text { (MeV.) }\end{array}$} & \multirow{2}{*}{$\begin{array}{l}\text { Circulat- } \\
\text { ing beam } \\
\text { ( } \text { amp. })\end{array}$} & \multicolumn{2}{|c|}{ External beam } & \multicolumn{2}{|c|}{ Analysed beam } \\
\hline & & & $\begin{array}{c}\text { ('urrent } \\
\text { (uamp.) }\end{array}$ & $\begin{array}{l}\text { Energy } \\
\text { spread } \\
\text { (MeV.) }\end{array}$ & $\begin{array}{l}\text { Current } \\
\text { ( } \text { amp.) }\end{array}$ & $\begin{array}{l}\text { Energy } \\
\text { spread } \\
\text { (MeV.) }\end{array}$ \\
\hline $\begin{array}{l}\mathrm{D}^{+} \\
\mathrm{H}_{2}^{+} \\
\mathrm{He}^{++}\end{array}$ & $\begin{array}{l}20 \\
20 \\
40\end{array}$ & $\begin{array}{c}250-350 \\
50-100 \\
10-25\end{array}$ & $\begin{array}{c}40-70 \\
10-20 \\
1-7\end{array}$ & $\begin{array}{l}1 \\
1 \\
2\end{array}$ & $\begin{array}{l}4 \\
1 \\
0 \cdot 1\end{array}$ & $\begin{array}{l}0 \cdot 15 \\
0 \cdot 15 \\
0 \cdot 3\end{array}$ \\
\hline
\end{tabular}

The photograph (Fig. 1) shows an analysed beam of $20-\mathrm{MeV}$. deuterons with a density of 1 uamp. $/ \mathrm{cm}^{2}$ and an angular spread of $1 / 10^{\circ}$ vertically and $2^{\circ}$ horizontally emerging into the observation chamber. When molecular hydrogen ions are accelerated, collisions between the ions and gas molecules in the tank during acceleration give rise to protons of half the incident energy, which return to the ion source and rapidly make it white hot. Fig. $2 a$ is a photograph of the tip of the ion source taken through a window in the tank wall under these conditions; Fig. $2 b$ is a similar photograph taken while the machine was accelerating deuterons.

Targets may be given high intensities of bombardment in the circulating beam, in vacuum in the exit port, or in air outside the exit port window, activities of many curies being obtainable with the shorter-lived. products. In many cases the intensity of the bombardment is limited by the difficulties of target-cooling rather than by cyclotron performance. Thermocouples in the target-cooling system are convenient for monitoring the beam current in high-intensity bombardments; power inputs of several kilowatts to suitable targets have been used.

Experiments in progress with the cyclotron include studies of nuclear reactions induced by bombardment with helium-3, elastic and inelastic scattering of protons and deuterons by nuclei, angular and energy distributions of products of $(d p),(d \alpha)$ and $(d t)$ reactions, and the investigation of short-lived activities. For the latter work the cyclotron ion source may be pulsed by a circuit synchronized with an external time base. Such experiments must all be done on or near the machine; in addition, many long-lived radioisotopes can, of course, be made, and some have already been distributed to users through the Isotope Division of the Atomic Energy Research Establishment, Harwell. Isotopes required by members of the University of Birmingham can be processed chemically in the radiochemical laboratory of the Department. The cost of operating the cyclotron in power alone is at present in the neighbourhood of $£ 2$ per hour, and the machine normally runs for 40-60 hr. per week, with one day set aside for routine maintenance.

The background of neutron- and gamma-radiation produced by the cyclotron is very large near the target, a fast neutron flux of about $10^{8}$ neutrons per $\mathrm{cm} .^{2}$ per sec. being obtained in the forward direction one metre from a beryllium target bombarded by 30 uamp. of $20-\mathrm{MeV}$. deuterons. The cyclotron is surrounded by water tanks and concrete blocks to a thickness of $40 \mathrm{in}$., and in occupied regions in the neighbourhood the radiation intensity does not exceed the maximum permissible level.

The completion and successful operation of the Nuffield Cyclotron was made possible only by the combined efforts of a large number of individuals. Nearly the whole machine was constructed by the workshop and scientific staff of the Physics Department, and the assembly of the major parts of the equipment was also the responsibility of members of the laboratory. By comparison with later cyclotrons some deficiencies in the engineering of the machine are apparent, but the general serviceability and performance since 1950 have been good. The Department has the satisfaction that the time and effort expended on construction have been rewarded not only by the success of the machine, but also by a detailed appreciation of its operating characteristics.

"Fremlin, J. H., and Gooden, J. S., "Cyclic Accelerators", Reports on Progress in Physics, 13, 295 (1950).

\section{UNDER-WATER TELEVISION AND MARINE BIOLOGY}

\section{By DR. H. BARNES}

Scottish Marine Biological Association, Millport

$\mathrm{A}^{\mathrm{s}}$

ITHOUGH in recent years there have been some advances in technique, notably in the use of the echo-sounder and in the development of the Hardy continuous plankton recorder, the marine biologist still relies to a very large extent on old methods for obtaining his 'field' information on the ecology of marine animals. The standard equipment such as nets, grabs and trawls have certainly been improved by various modifications, and their method of working and the results obtained have been subjected to a more critical examination; but such equipment can only give limited information regarding both the detailed distribution and behaviour of the animals in their natural habitats. In this sense progress in marine biology has not kept pace with that in physical oceanography, where there has been considerable technical advance, particularly in respect 
of methods which are required to obtain an approach to a synoptic picture.

In a number of laboratories, under-water photography has recently been considerably developed as a biological technique, and some valuable results have been obtained in this way. However, this method suffers from a number of rather severe limitations. If the camera is manually operated it is necessary to employ a qualified diver or specially trained personnel, and unless only very moderate depths are to be explored complete diving equipment is necessary: even so, unless resort is made to equipment such as the bathysphere, the depths that can be investigated in this way are still only moderate in comparison with those at which marine animals are known to live; further, the time available for any one series of observations is limited. On the other hand, if the camera is operated from a ship, the investigator has no knowledge of what he is looking at, so that much time and film is wasted, and further, unless a cinécamera is used, the pictures of living and moving objects taken in this way are often difficult to interpret.

The announcement by the Admiralty of the use of under-water television in its work clearly raises the possibility of its uses in marine work in general. In fact, an under-water television project for use in marine science had been under development for some time before this announcement was made. Preliminary inquiries were begun in 1948, and in the following year, as a result of the kind co-operation of Dr. E. Hindle in granting facilities at the Aquarium of the Zoological Society of London, it was possible to demonstrate with a large variety of marine animals the quality of picture (from the zoological point of view) which might be approached. The demonstration was arranged by the E.M.I. Research Laboratories, which from the very first inquiries had shown keen interest in this project.

As a result of this preliminary work the Council of the Scottish Marine Biological Association, under its president, Prof. C. M. Yonge, made application to H.M. Treasury for a grant from the Development Fund : the matter was referred to the Development Commission's Advisory Committee on Fisheries Research. A grant was recommended and a scientific group set up under the chairmanship of Prof. A. C. Hardy, with which group the development of the project was to be in close contact.

The equipment, which is now almost ready, is being made by the E.M.T. Research Laboratories, and the C.P.S. Emitron camera equipment is being employed. It is anticipated that in the use of underwater television in the marine biological sciences the 'picture quality' will be of paramount importance. Under the term 'picture quality' are included such factors as adequate definition, complete freedom from shading and fidelity of picture tone quality-all these factors resulting in a picture of photographic quality. In all these respects it would seem that the C.P.S. Emitron camera is as adequate as any of the systems so far developed.

In order to give facility for observation, remote control of iris, focusing and lens turret (giving wide range of lens angle) have been developed and are incorporated in the equipment. In the first instance the development and use of the equipment is to be carried out on board the research ship of the Association, the 75-ft. M.V. Calanus; the layout of the control, power and viewing units has therefore been specially designed for working in a small space. The boat has available $7 \mathrm{~kW}$. of power, and a converter has been installed to provide alternating current for the equipment $(2 \cdot 5 \mathrm{~kW}$.).

While the equipment has been under manufacture, opportunity has been taken of making some preliminary investigations using prototype equipment. This work has been done at Millport in the large concrete tank used for oyster investigations. In this tank, which is $60 \mathrm{ft}$. long, $30 \mathrm{ft}$. wide and $7 \mathrm{ft}$. deep, lighting, turbidity and equipment may be readily controlled, for the difficulties inherent in handling the gear on board ship are absent. The tests included examination of fish, bottom fauna and plankton under varying conditions of lighting and turbidity. (The latter was estimated by means of a modified Pettersson instrument, and the results are quoted as percentage transmission of the value in air.) A number of modifications in the equipment were tested, including some camera tubes specially designed for the project. The results have so far been very encouraging. For example, using a $2 \frac{1}{2}$-in. lens with a turbidity of 73 per cent, adult cod (about 18 in. in length) were readily distinguished by their ordinary 'zoological' features at $16 \mathrm{ft}$. In a turbidity of 63 per cent the 'twitching' of the antennules of moderate-sized crabs could be readily seen at $6 \mathrm{ft}$., the lens magnification available allowing more detail to be seen than would be possible by direct visual observation at this distance and under these conditions. The planktonic euphausid Meganyctiphanes norvegica was very clearly seen in the latter turbidity at $1 \mathrm{ft}$., the rapid motion of the fine appendages being quite visible. The accompanying photograph of this species is believed to be the first one of a plankton organism to be taken through under-water television. For the purpose of comparison it may be stated that the turbidity of the sea in this area was about 86 per cent during the course of these experiments.

There are, no doubt, many problems to be solved; some will relate particularly to specific uses of the

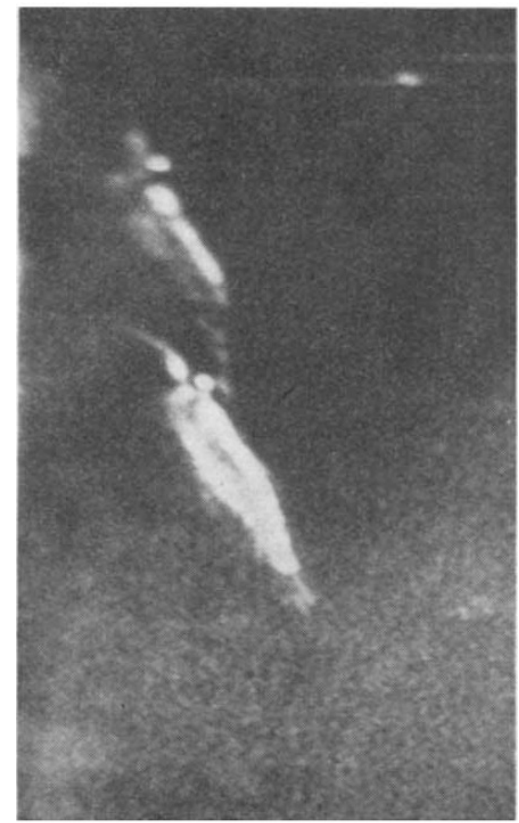

The euphausid Meganyctiphanes norvegica photographed by underwater television 
new technique, while others will relate to the working of the equipment on board a small ship. Further, as with all other methods, under-water television will have its limitations, but the preliminary results support the view that it will be a valuable addition to the techniques available for marine biological work.

In the development of complicated and expensive equipment such as is required in this work, help is needed from many sources. I wish to acknowledge a deep debt of gratitude to all those who have given of their assistance and advice, in particular to Prof. A. C. Hardy and to Dr. J. D. McGee (of E.M.I.), who from the very beginning have encouraged the project; to the Development Commission for recommending, and H.M. Treasury for making, a generous grant; to the management of E.M.I., particularly to Mr. G. E. Condliffe, director of research, and to Mr. P. L. Johnson and his colleagues for all their work in the preliminary investigations.

\section{ALCHEMY AND ART* \\ By PROF. JOHN READ, F.R.S.}

A $\mathrm{T}$ the outset it must be emphasized that alchemy was more than a rudimentary form of experimental science. In its widest aspect it was a philosophical system. In their true significance, the efforts of the adepts to transmute metals were attempts to prove the truth of the broad philosophical system of alchemy by means of material experiments.

Alchemy endured for more than a millennium; but it has long been outmoded, and there is little realization at the present day of the extent to which alchemical conceptions and imagery permeated the thought and art of the Middle Ages ${ }^{1}$.

Art played an important part in alchemy. In examining this part in some detail it is impracticable in this place to do more than select a few outstanding items from the prodigious array of alchemical literature.

First, there are many beautiful alchemical manuscripts, often adorned with drawings or paintings. For example, an illustration in a fifteenth-century manuscript version of Norton's "Ordinall of Alchemy", a work written in 1477, in rhymed English verse, shows the Bristol alchemist, Thomas Norton, seated before a balance ${ }^{2}$. This illustration was later engraved by Thomas Vaughan for Ashmole's "Theatrum Chemicum Britannicum" of 1652 , which contained the first printed version of the "Ordinall". Vaughan modified the original drawing and provided it with a characteristic ornamental border ${ }^{3}$. Incidentally, the original rendering possibly contains the earliest representation of a balance enclosed in a case.

One of the most beautiful and artistic of all alchemical manuseripts is the copy of Trismosin's "Splendor Solis" in the British Museum. This Harley MS. 3469, dated 1582 , is a striking example of an alchemical manuscript of the late medieval period. It consists of a German text of forty-eight leaves, illuminated in gold, with twenty-two coloured allegorical paintings of great beauty, representing alchemical ideas and processes.

The fifth of seven paintings of the Hermetic Vessel, or Philosopher's Egg, depicting successive operations

* Substance of a Friday Evening Discourse delivered on March 14 at the Royal Institution, London. of the Great Work, shows the stage at which the colours of the peacock's tail were supposed to appear in the Vessel. The brightness and freshness of the colours in the original are very remarkable ${ }^{4}$.

With the arrival of printed books, engravings supplanted the earlier kinds of pictorial representation. Alchemical engravings began with the woodcut, from which, as in the outer world of art, there was a gradual movement, first to the copper plate and etching, and later to the stipple engraving and mezzotint.

Some of the earliest woodcuts of chemical interest are to be found in works dealing with severely practical applications of the incipient science, rather than with the nebulous and mystic aspects of alchemy. In 1474 appeared Puff's "Von Den Gebrannten Wassern", with its bold unhatched woodcuts in the stiff and angular Gothic style.

Another early work dealing with the same subject of distillation from the practical point of view was Brunschwick's "Destillierbuch", first published in 1500 at Strasbourg. Grüninger's cuts, in this and other books, often have a silvery appearance evoked by numerous parallel unhatched lines. Sometimes an illustration of a piece of apparatus includes also a glimpse of a medieval panorama. Occasionally the engraver achieves an outstanding design ${ }^{5}$.

One of the earliest surviving representations of a medieval alchemist at work is a woodcut by Hans Weiditz, a leading illustrator of the Augsburg school, who was known as the Petrarcameister. This woodcut 6 was executed about 1520 , and first appeared in the "Trostspiegel", a German translation of Petrarch, in 1532. In the melancholy air of the alchemist and his assistant we may perceive an element of caricature.

The feeling of these German woodcuts and books is very different from that of the Aldine publication "Pretiosa Margarita Novella", printed by Paolo Manuzio at Venice in 1546. The somewhat lifeless woodcuts ${ }^{7}$ show little cross-hatching; but in their greyness they form a harmonious balance with the delicate italic type. This book, which was sold somewhat later to the printer Ziletti, is one of the few illustrated Aldine publications, and is much valued by collectors.

At about this time, in 1556, was published at Basle that great medieval work on mining and metallurgy, Agricola's "De Re Metallica". It is a handsome work in folio, profusely illustrated with woodcuts. These give an admirable idea of processes and machinery, although they lack the real artistic fire ${ }^{8}$.

Most of these early alchemical engravings delineated apparatus and practical operations. It was early in the seventeenth century, when alchemy had already begun to wane, that some of the most interesting and artistic engravings were produced. This period coincided with the development of copper engraving.

Outstanding among these engravings are the beautiful creations at Frankfurt-on-Main of the two de Brys and their successors, Merian and Fitzer, who married two daughters of Johannes Theodorus, the younger de Bry ; Fitzer, a Londoner, espoused the youngest daughter in 1625 .

The most noteworthy of these alchemical engravings occur in various works of Count Michael Maier, and especially in "Atalanta Fugiens", published at Oppenheim in 1618.

Particularly noteworthy is de Bry's ornamental title-page ${ }^{9}$ of the work, in which, incidentally, Maier 